\title{
Effective Polysulfide Adsorption by Double Side Coated Separator in Lithium-Sulfur Batteries
}

\author{
Yulin Liu ${ }^{1}$, Jing Li $^{1,2^{*}}$, Min Zeng ${ }^{1}$, Xun Xu $u^{1}$, Jianna Deng ${ }^{1}$, Jianqiang Guo ${ }^{1}$, Dan Zhao ${ }^{2}$, Jianzhao \\ Yang ${ }^{3}$, Hongru Wang ${ }^{1}$, \\ ${ }^{1}$ Institute of Material Science and Engineering, Southwest University of Science and Technology, \\ Mianyang, 621010, Sichuan, China. \\ ${ }^{2}$ Sichuan Xike Six Timbers Hi-tech Corporation, Mianyang 621010, China \\ ${ }^{3}$ School of Environment and Resources, Southwest University of Science and Technology, Mianyang, \\ 621010, Sichuan, China. \\ *E-mail: 195216521@qq.com
}

doi: $10.20964 / 2018.08 .28$

Received: 17 March 2018 / Accepted: 6 May 2018 / Published: 5 July 2018

Lithium-sulfur batteries have attracted much attention because of their high specific capacity and energy density. However, the commercialization of lithium-sulfur batteries is limited by low utilization of active materials and excessive capacity decay which caused by the shuttle effect of polysulfide in the practical applications. In this article, effective polysulfide adsorption method was applied via using modified PP separator coated super $\mathrm{P}$ and $\mathrm{Al}_{2} \mathrm{O}_{3}$ on the two sides, respectively. As a result, this strategy solves the problems of polysulfide shuttle effect and poor sulfur conduction at the same time. The initial discharge specific capacity of lithium-sulfur batteries, which assembled with the super $\mathrm{P}+$ $\mathrm{PP}+\mathrm{Al}_{2} \mathrm{O}_{3}$ separator, could reach $1247 \mathrm{mAh} \mathrm{g}^{-1}$ at the current density of $0.1 \mathrm{C}$. After 60 discharge / charge cycles, the discharge capacity was still $987 \mathrm{mAh} \mathrm{g}^{-1}$, with a capacity retention of $79 \%$. This method of simultaneous modification on both sides of the separator provides a new idea for the modification of lithium-sulfur batteries.

Keywords: super P layer, PP separator, $\mathrm{Al}_{2} \mathrm{O}_{3}$ layer, shuttle effect, electrochemical performance

\section{FULL TEXT}

(C) 2018 The Authors. Published by ESG (www.electrochemsci.org). This article is an open access article distributed under the terms and conditions of the Creative Commons Attribution license (http://creativecommons.org/licenses/by/4.0/). 